\title{
Creating Digital Learning Resources as WEB services
}

\author{
Vladimir Rueda Bermúdez ${ }^{1}$ \\ ${ }^{1}$ Universidad de Medellín \\ Carrera 87 No. 30-85 - Medellín - Antioquia - Colombia \\ vrueda@udem. edu.co
}

\begin{abstract}
This meta-paper describes a contextual approach to virtual teaching and places special emphasis on the use of DLR (Digital Learning Resources), and the difficulties inherent in its implementation on platforms, since its creation, the need for interoperability, search and validation of the same.

The possibility of taking advantage of web services is proposed, in the design of a method that allows the co-creation of VLO (Virtual Learning Objects), fulfilling some work objectives and developing an experimental validation process to measure the achievement of the proposed objectives.
\end{abstract}

Keywords - Learning platforms, Virtual learning objects, Web services, MOOC, Digital Learning resources

Resumo. Este meta-artigo descreve a abordagem contextual ao ensino virtual e dá ênfase especial à utilização de RED (Recursos Educacionais Digitais), e às dificuldades inerentes à sua implementação em plataformas, desde a sua criação, necessidade de interoperabilidade, pesquisa e validação das mesmas.

É proposta a possibilidade de usufruto de serviços web, na concepção de um método que permita a co-criação de VLO (Objetos Virtuais de Aprendizagem), cumprindo alguns objetivos de trabalho e desenvolvendo um processo de validação experimental para medir o cumprimento dos objetivos propostos.

Palavras-chave- Plataformas de aprendizagem, Objetos virtuais de aprendizagem, Serviços da Web, MOOC, Recursos educacionais digitais

\section{Introduction}

The purpose of this report is to present an updated view of the current state of use of VLO in education and to describe a methodological proposal for the design of a method, based on specific VLO prototypes as web services.

This article is intended for an audience of researchers, teachers and content creators, from the technological context of virtual education, web services, co-creation; The results of a systematic literature review are shown, which support the research problem.

Then the methodology used in the research process is presented, the method proposal for the creation of OVA; It also describes the validation test and its results, the conclusions of the research and possible future work. 


\section{Context}

\subsection{Virtual learning environment}

Although there are independent models and specific processes for teaching, they can formally be distinguished as learning systems [Cañelas, 2012].

- $\quad$ CMS (Content Management Systems) Content management system

- $\quad$ LMS (Learning Management Systems) Learning management system

- LCMS (Learning Content Management Systems) Content management system for learning

- VLE (Virtual Learning Environment): Virtual environments created as teaching platforms.

In the VLO development methodology [Monsalve, 2011], it is referred to as one of the resources that has contributed the most methodological development to the learning process, and facilitates good practice in each of the phases of the proposed methodology. In addition, the author ensures that the quality of the virtual learning object can be guaranteed, carrying out an evaluation process iteratively, until obtaining the desired value according to international standards.

This standard definition, accompanied by the need for standardization, has allowed the creation of SCORM (Sharable Content Object Reference Model), IMS (Internet Media Services) and other packages in order to standardize and verify the creation of knowledge, and also use it in some platforms [Milano et al, 2016]. However, in this virtual learning process there are still some problems to be dealt with, from the perspective of the teacher and the end user.

\subsection{Web services}

A web service is a technology that uses a set of protocols and standards that solve these problems and serve to exchange data between applications. Different software applications developed in different programming languages, and executed on any platform, can use web services to exchange data on computer networks such as the Internet. Interoperability is achieved through the adoption of open standards.

In addition, it is suggested [Alonso et al, 2004] web services technology, designed for the communication of applications, presenting itself as an alternative for the technological advancement of applications and offering the following advantages: Interoperability, promotion of text-based standards and protocols, integrated combination of services more efficient search mechanisms.

\subsection{Co-creation}

It is a concept that originates as a business strategy. It is constituted in the development of activities in a collaborative way between the organizational actors and their clients, in order to build the product or service that they expect, need and want. Likewise, the concept has been used with significant relevance in the context of education, among others, and in processes of construction of Open Digital Educational Resources, as it focuses the contributions of the various actors towards the fulfillment of the preferences and needs of student learning, by including inclusion and accessibility 
features. Co-creation is a process that provides tools for communication and creativity at the service of those who will directly benefit from the results.

\subsection{Interoperable LDR (Learning digital resources)}

The interoperability possibilities found in web services technology and the similarity of its solution provided to the communication of applications [Fragoso, 2013], opens the expectation of its use as a resource to provide a new possibility in the dissemination and use of VLO as learning digital resources, which allows setting evaluation parameters to promote agility and future search criteria, in a similar way to how web services do today in an SOA environment.

\section{Methodology.}

To carry out this project, the science methodology based on information systems design has been chosen [Hevner et all, 2004] and the experimental design is proposed as a validation model, associated with the creation of VLO WEB SERVICES.

Review of specific methodologies that apply to the functionality of VLO as a WEB service, development of VLO prototypes as a test web service that allow to measure web functionality for access, development of the method based on the proposed methodology and prototypes that allows creating an VLO from scratch, until its publication as a web service, Measurement of the VLO method as a web service from creation to end use in a specific knowledge context.

\subsection{Systematic literature review VLO \& WEB SERVICES}

A systematic literature review is carried out to document and explore ideas in this regard, with the following search strings:

- Web services AND (learning objects OR learning web services) OR Learning Management System

- Web services AND (Virtual Learning OR Learning objects) For the composition of a SCORM package requires a knowledge of systems, equipment and tools at considerable cost [8].

These questions were applied to the following scientific databases IEEE,GoogleScholar, EBSCO.

In summary, there is difficulty in semantically normalizing the contents of SCORM and other educational standards on the Internet due to their domain connection with specific platforms [Hartonas \& Gana 2008].

The use of standards closed to the domain of learning objects such as SCORM, LOM (Learning Object Metadata) and DC (Dublin Core), also represents a problem for reuse [Fragoso, 2013].

\subsection{Prototyping}

VLO prototypes are developed as WEB applications to explore their operation without SCORM metadata and current methods for creating VLO in higher education are documented. With these records the methodological proposal is elaborated. 


\subsection{VLOWEB creation method}

This method would be part of the course creation process within a higher education context, in which there should already be a specific LMS platform, institutional templates, and the roles of co-creator teachers, co-creator students, pedagogical advisors and production team.

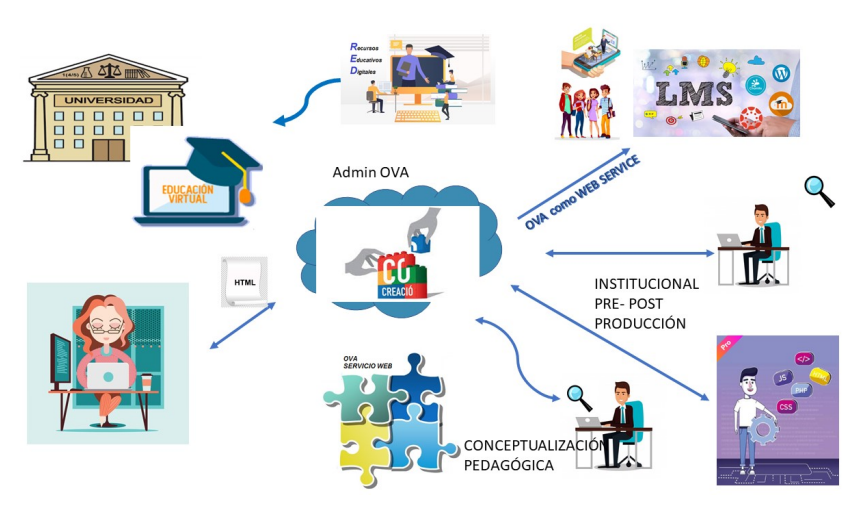

Figure 1. VLO WEB METHOD

Step 1. Create the CSS, HTML, ASSETS template: The ICT team must generate reusable templates that support the institutional image and the general dynamic structure of the course, including in this template an ASSETS folder with images and icons that can be used at the moment to create an application that contributes to learning. This template should include the VLO Representation and Metadata Schemes (SCORM) that will be described later.

Step 2. Design and configure virtual course: The ICT team creates the empty virtual course on the platform, including a cover page and a personalized scheme according to the institutional image that is to be projected to users, and leaves the spaces free for assignment of educational resources.

Step 3. Assign roles and tasks to teachers, students and pedagogical managers. The ICT team selects and assigns a creator teacher and an evaluator peer for the purpose of creating the course content. From this process comes the requirement of creating $\mathrm{VLO}$ as a resource for monitoring and validating learning.

Step 4. Configure web services on the platform: Each platform must allow the execution of web services that allow external integration. These services must be configured to generate an integration token for access and thus allow external VLO to maintain their independence and at the same time be part of a Virtual Course.

Step 5. VLO co-creation: Once the creator teacher has prepared the base prototype VLO, it is available in the review repository for adjustments, changes and observations. From that moment on, this VLO is reviewed by the ICT technical team in order to verify its content and link to the mission of the institution and its corporate image, in addition to the validation of copyright and legal aspects of the document created, the same that the dynamics of updating and changes that are required.

Step 6. Publication of the VLO: If there are observations, the respective request is made and sent to the teacher for review. The pedagogical advisor is not part of the 
process from the technology, but their contributions are made when defining the adaptations of the prototype VLO to the suggested changes.

Step 7. Add service request: Once the VLO is reviewed and the web service configuration is available on the platform, we proceed to add the services layer to the VLO, services that will allow future users to find the VLO, describe it and also review the fields that are sent to synchronize with the local platform.

Step 8. Publish the VLO: The ICT team publishes the VLO already ready so that any teacher can add it in the section they want within their course. Then, the VLO is indexed in the repository and available to be reused in another context, using its description and its specification (JSON). Also, the metadata is made available to semantically access the VLO.

Step 9. Add VLO to the course: The ICT team adds the VLO as a training resource to be used within the virtual course.

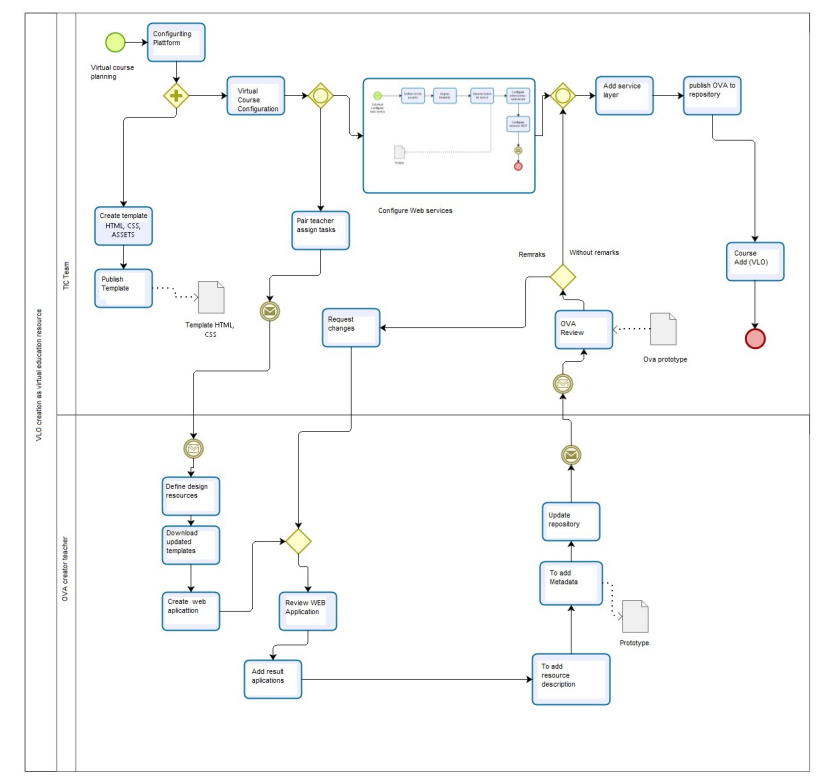

Figure 2. Specific Bizagi VLO WEB METHOD

\subsection{Validation}

The statement of the project requires a controlled scenario in which tests and measurements of functionality and compatibility can be carried out, all this on a sample of teachers, students and the learning object production team. For this reason, the type of validation to be applied is that of an experimental investigation.

This validation scheme proposes as subjects of the experiment: Teachers and student's co-creators of specific areas of knowledge, VLO production team, with a similar level of expertise in years, students who validate the created VLO and pedagogical advisers with mastery of LMS platforms.

The creation of an VLO as a web service, using the platform and the proposed method, in the same context of the base treatment, with another team of teachers and another team of developers. 


\subsubsection{Independent variables}

VLO of the specific area: Corresponds to the minimum objectives or goals desired for the creation of the VLO, which are defined by the Ministry of ICT, context, content and learning activity. Also, expertise of content creators and LMS Platform

\subsubsection{Dependent variables}

Method functionality. Defined from the ISO 9126-2 standard as an external metric, it allows to measure the attributes of functional behavior, and that in the ISO 25000 standard represents the capacity of the software product - in our case the method -, to provide functions that satisfy the declared needs and implicit, when used under specified conditions, in our case the minimum VLO requirements. This variable can be represented by the following metrics:

Functional completeness. Degree to which the set of functionalities covers all the specified user tasks and objectives.

$$
\mathrm{Cf}=\sum \mathrm{fe} / \sum \mathrm{fu}
$$

$\mathrm{fe}=$ expected functionalities $\mathrm{fu}=$ functionalities used

Functional correction. Ability of the product or system to provide correct results with the required level of precision.

$$
\mathrm{Cf}=\sum \mathrm{Vc} /(5 \times 5 \times 4)
$$

$\mathrm{Vc}=$ Assessment of each characteristic in each case

Functional relevance. Ability of the software product to provide an appropriate set of functions for specified user tasks and objectives.

$$
\mathrm{Pf}=\sum \mathrm{Ce} / \sum \mathrm{Tc}
$$

$\mathrm{Ce}=$ Assessment of successful cases $\quad \mathrm{Tc}=$ Total case studies

Coexistence. Product ability to coexist with other independent software, in a common environment, sharing common resources without detriment.

$$
\text { Coex }=\left(\sum \text { call }-\sum b q\right) / \sum \text { call }
$$

call $=$ Number of service calls $\quad b q=$ Number of locks

Interoperability. The ability of two or more systems or components to exchange information and use the information exchanged.

$$
\text { Iop }=100-\sum \mathrm{ec} / \sum \mathrm{R}
$$

$\mathrm{ec}=$ Errors in sending information packages $\mathrm{R}=$ total responses from the service

Satisfaction criteria: $90 \%$ functionality metrics of the proposed method, and $80 \%$ compatibility level of VLO with the LMS platform.

\section{Results of the validation process}

Once the variables, roles and case studies that should be part of the test have been defined, the validation protocol is designed that allows the functional information of the method and the resulting VLO to be recorded, following the following phases and obtaining the respective results. 
Phase 1. Selection and formalization of validation subjects.

Phase 1 result: VLO-WEB validation participant registration form, Project contextualization videos:

Validation context 1: https://www.youtube.com/watch?v=XaXOpkvGVXQ

Validation context 2: https://www.youtube.com/watch?v=FeEtXbqUWwU

Phase 2. Formation of co-creation teams.

Phase 2 result: See table 1. VLOWEB working groups

Phase 3. Training of the project context and expected results

Phase 3 result:VLO Training Video: https://www.youtube.com/watch? $\mathrm{v}=8 \mathrm{xrUqLJkWjU}$

AdminVLO Training Video:https://www.youtube.com/watch?v=xnuqWZHafEs

Phase 4. Co-creation of VLO.

Result phase 4: 9 VLO of different knowledge areas, co-created and available on the ADMINVLO platform, stored with their history of records and modifications. Registration of validation forms of the case functionality of the method, validation of the resulting VLO and Validation of method functionality.

Phase 5. Using VLO as a web service.

Result phase 5: Integration of the VLO created to the MOODLE platform, registration of compatibility validation forms.

Phase 6. Tabulation of the data obtained. The data obtained from each case study is tabulated and the final validation report is made.

Phase 6 result: VLOWEB validation report, see table 1.

Table 1. Validation report

\begin{tabular}{|c|c|c|c|c|c|c|c|}
\hline \multicolumn{8}{|c|}{ INFORME DE VALIDACIÓN DEL METODO PARA LA CO-CREACIÓN DE OVA COMO SERVICIO WEB } \\
\hline FUNCIONALIDAD DEL MÉtOdo & & & & VALDAC & CIÓNDE & ELL METODO & \\
\hline CASOS DE ESTUDIO & If & $\mathrm{Fa}$ & $\mathrm{fg}$ & $\begin{array}{l}\text { Completitud } \\
\text { funcional } \\
\text { cf }=\sum \text { ff } / \Sigma \\
\text { fa }\end{array}$ & $\mathrm{v}_{\mathrm{c}}$ & \begin{tabular}{|l|} 
Corrección \\
funcional \\
$c f=\sum V_{C}$ \\
cf $=$ ( TF $\times 5$ ) \\
\end{tabular} & $\begin{array}{l}\text { Pertinencia } \\
\text { funcional } \\
P f=\Sigma C e / \Sigma T c\end{array}$ \\
\hline METODO DE CO-CREACION DE OVAWEB & 12 & 60 & 55 & $92 \%$ & 292 & $97 \%$ & $95 \%$ \\
\hline TOTALES & 12 & ${ }_{60}$ & 55 & $92 \%$ & 292 & $97 \%$ & $95 \%$ \\
\hline FUNCIONALIDAD DEL MÉTODO & \multicolumn{7}{|c|}{ VALIDACIÓN DE OVA RESULTANTES } \\
\hline CASOS DE ESTUDIO & If & fa & fo & 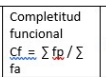 & $v_{c}$ & \begin{tabular}{|l|} 
Corrección \\
funcional \\
$c f=\sum \times c /$ (tf $*$ \\
$5 \times 5$ ) \\
\end{tabular} & 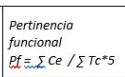 \\
\hline EL PÉNoULo & 3 & 15 & 12 & $80 \%$ & 69 & $92 \%$ & $87 \%$ \\
\hline LA CUARTA REVOLUCION INDUSTRALL & 3 & 15 & 13 & $87 \%$ & 67 & $89 \%$ & $80 \%$ \\
\hline GESTIÓN DE ALMACENES & 3 & 15 & 14 & $93 \%$ & 69 & $92 \%$ & $87 \%$ \\
\hline EL RITMO & 5 & 25 & 21 & $84 \%$ & 109 & $87 \%$ & $84 \%$ \\
\hline LA CUMBIA & 4 & 20 & 18 & $90 \%$ & 87 & $87 \%$ & $85 \%$ \\
\hline CULTURA EN EL PROCESO DE ENSEÑANZA & 4 & 20 & 19 & $95 \%$ & 93 & $93 \%$ & $90 \%$ \\
\hline LA DOBLE INSTANCIA & 2 & 10 & 9 & $90 \%$ & 49 & $98 \%$ & $90 \%$ \\
\hline LEY DE ALMMENTOS & 2 & 10 & 10 & $100 \%$ & 42 & $84 \%$ & $90 \%$ \\
\hline COSTO DE CAPITAL PROMEDIO & 2 & 10 & 9 & $90 \%$ & 46 & $92 \%$ & $90 \%$ \\
\hline TOTALES & 28 & 140 & 125 & $89 \%$ & 631 & $90 \%$ & $87 \%$ \\
\hline
\end{tabular}




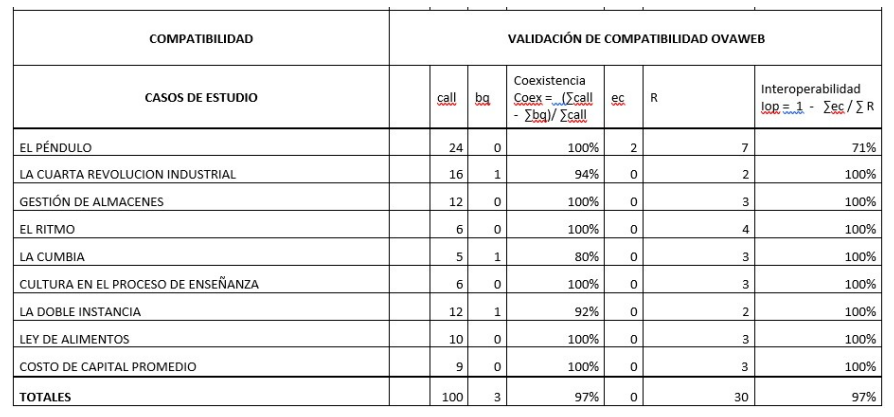

\section{Analysis of results}

\subsection{Method functionality}

For the analysis of this variable, we must remember that three metrics were established: Functional completeness, functional correctness, and functional relevance. In addition, keep in mind that they were measured separately both for the resulting VLO and for the proposed method.

\subsection{Functional completeness}

A general average of $92 \%$ is achieved in the method and $89 \%$ in the resulting VLO.

The proposed method covers most of the functions required in an VLO creation method, and although the VLO created are basic, it is also possible to fulfill a very high percentage of the functionalities that are expected by co-creation teams. .

According to this criterion, the scope proposed for the experiment minimally limits the real expectations of the teachers and student co-creators when approaching the created VLO, but, even so, the method is maintained as a good alternative for the co-creation process.

Functional correction: Results $97 \%$ in the method and $90 \%$ in the VLO created. Functional relevance $95 \%$ for the method and $87 \%$ for the VLO created.

Compatibility of the VLO created

Coexistence Result 97\%.

Interoperability Result 97\%

\section{Conclusions and future work}

The method that is proposed for the co-creation of VLO as web services, the main objective of this project, is presented as an alternative that enables the participation of various roles in a production process of this digital learning resource. This method is functional and can coexist with other methods of co-creation of digital resources, providing additional design data that allow for semantic and evolutionary traceability of the VLO.

The subsequent provision and use of VLO as web services can be based on the possibility of interoperability offered by web services for the appropriation by different platforms sharing information with this type of architecture, however, the integration process still depends to a great extent It starts from the knowledge of the platform and requires specialized personnel to achieve good results. 
In this exercise, interoperability with the MOODLE platform of 9 VLO is achieved, which have been co-created in the ADMINVLO platform by three teams made up of teachers and students, who are advised by a group of pedagogical professionals and producers. This integration is achieved by taking advantage of the web service resource as a MOODLE external resource tool and the identification token.

For the update of the notebook the core_grades_update_grades function and the variable moodlewsrestformat of type json with the values referring to the course being updated.

Although the co-creation tests were carried out asynchronously to validate the project, the technology that currently exists allows the synchronization of different actors, and this field is left open for further research that allows to extend the validation of usability, re-use and semantic organization processes of VLO repositories.

This project presents a scope of basic VLO, thinking about the possibility of creating small independent cells of knowledge that can later be linked, also in an evolutionary way to create knowledge networks from intelligent repositories that allow the weighting of the VLO created according to their use, quality acceptance and other specific indicators that allow to take advantage of artificial intelligence technologies for the selection and categorization of VLO, at the moment in which the repository increases the volume of VLO from the histories to the published VLO.

\section{References}

Cañellas, A, P. (2012). CMS, LMS and LCMS. Definition and differences, @ www.centrocp.com. (nd). Retrieved fromhttp://www.centrocp.com/cms-lms-y-lcmsdefinicion-y-diferencia/

Monsalve, P, A, Aponte; N. (2011). MEDEOVAS -Methodology for the Development of Virtual Learning Objects. Retrieved from http://docshare02.docshare.tips/files/26885/268859589.pdf

Milano, E., Vieira, F., De Moraes, M., \& Rossato, J. (2016). Evaluation of Virtual Objects: Contributions for the Learning Process. International Review of Research in Open and Distributed Learning, 17 (6) ..

Alonso G., Casati F., Kuno H., Machiraju V. (2004) Web Services. In: Web Services. Data-Centric Systems and Applications. Springer, Berlin, Heidelberg.

Fragoso, OG, Santaolaya, R., Rojas, JC, Muñoz, J., \& Valenzuela, BD (2013). Web Services for Electronic Learning. Research in Computing Science, 64 (Advances in Information Technology).

Hevner, AR, March, ST, and Park, J. "Design Research in Information Systems Research", Mis Quarterly (28: 1) 2004, pp 75-105.

Hartonas, C., \& Gana, E. (2008). Learning Objects and Learning Services in the Semantic Web. In 2008 Eighth IEEE International Conference on Advanced Learning Technologies (pp. 584-586). IEEE.http://doi.org/10.1109/ICALT.2008.56.

Sánchez M, II (2015). State of the art of the methodologies and models of Virtual Learning Objects (OVAS) in Colombia. Revista Surroundings, 2 (28), 93-107. Retrieved from http://journalusco.edu.co/index.php/magazine/article/view/472/1265. 